\title{
The Investigation of Mobility Levels of Postoperative Patients Open Heart Surgery and Influencing Factors
}

\author{
Fadime Çinar* \\ Department of Health Sciences Sabahattin Zaim University, Turkey
}

*Corresponding author: Fadime Çinar, Department of Health Sciences Sabahattin Zaim University, Istanbul, Turkey.

Received Date: February 01, 2020

Published Date: February 18, 2020

\begin{abstract}
Objective: The aim of this study was to investigate the mobility levels of the patients who had open heart surgery and influencing factors the postoperative period.

Method: This is a descriptive cross-sectional study. The study sample consisted of 118 patients who had open heart surgery in a cardiovascular surgery clinic of a cardiovascular surgery training hospital. The study was conducted between October and December 2018 in a 3-month period. The mobility difficulties experienced by the patients and their activity levels during the postoperative period were evaluated using the Patient Mobility Scale and the Observer Mobility Scale. The data were analyzed using SPSS 25.0 software.

Results: $41.7 \%$ of patients returned to the other side of the bed, $36.3 \%$ had to sit on the edge of the bed and $32.8 \%$ had oral warning and physical help while walking in the room, while $27.4 \%$ stand up independently with verbal warning on the edge of the bed. they were able to get up. The results showed that the patients were unable to turn independently from one side of the bed to the other.

Conclusion: The findings of this study are significant in order to show that the patients who have undergone open heart surgery to increase the level of movement in early postoperative period will have a positive effect on the overall recovery process of the patients.

Keywords: Postoperative period; Open heart surgery; Moving the patient; Early standing up
\end{abstract}

\section{Introduction}

Surgical applications, which are frequently used as a treatment method in the healing of patients, have increased in recent years with technological advances in the field of health. With this increase, traditional approaches are being replaced by evidencebased practices in order to reduce morbidity, accelerate recovery and shorten the recovery period after surgical treatment. With these changes in the surgical field, rapid recovery was achieved and hospital stay was significantly shortened [1,2]. Cardiac surgery is one of the surgical areas where rapid changes occur. Nowadays, the most commonly used method in the surgical treatment of heart diseases is open heart surgery. Open heart surgery; Open heart surgery, which is used in the surgical treatment of heart diseases, is a basic treatment for coronary artery disease, heart valve diseases, congenital lesions and heart transplantation [3]. Early mobilization and mobilization of the patient as soon as possible after surgery prevents complications related to inactivity.
Maintaining homeostatic balance and accelerating recovery are important goals of postoperative care [4]. Cardiovascular and respiratory complications associated with surgery are reduced with early uplifting. Wound healing and intestinal peristalsis are supported. The development of thrombophlebitis is prevented, and the patient is assured to take care of himself/herself as soon as possible. Despite the effects of early standing up on homeostatic balance and recovery, the patient may not be willing to perform these activities after surgery or may have fears about movement [5]. Circulatory problems (orthostatic hypotension, venous stasis, thrombus formation), urinary retention, respiratory problems, constipation and development of negative nitrogen balance may occur in patients who have been inactive for a long time after surgery, and pressure sores may occur on the skin [6]. Postoperative early stand up is an important component and it is recommended that even intensive care patients undergoing radical surgery should 
be mobilized within the first 24 hours, provided that their survival is stable [3].

Mobilization, which is performed in the form of a few steps at the bedside during the postoperative period of 6-8 hours, is referred to as early stand up. It is recommended that the patient spend 2 hours in the first 24 hours on the day of surgery and 6 hours out of bed until discharge on the following days [7-9]. Again, in various studies; in patients who were removed early postoperatively, the length of hospital stay was significantly shorter; physical, social and psychological well-being of patients was reported to be higher [913]. Due to the positive effects of early uplifting after surgery, the nurse has important responsibilities for the patient to plan early uplifting within the first 24 hours, to ensure patient safety, and to plan patient-specific care bundles including enteral nutrition and effective pain management. Considering the important positive outcomes such as early mobility, reduced organ dysfunction and morbidity in patients, and early discharge from hospital, the awareness and skills of nurses who have the opportunity to monitor the patient for the longest period in the postoperative period gain importance [11-15]. Postoperative mobility and activity regulate respiration and reduces the accumulation of secretion in the lungs [16]. It also decreases postoperative abdominal distension by accelerating peristalsis, increasing abdominal wall tone and gastrointestinal system functions, and thrombophlebitis and phlebothrombosis are less common in these patients as they accelerate venous return by accelerating circulation in the extremities. Postoperative early stand up of the patient supports pain control, shortens the hospital stay and reduces the cost of care [17]. Activity planning should be made considering the patient's tolerance to activities may vary according to the type of surgery, age and physical condition. In-bed activities are continued to accelerate circulation. Postoperative sensory and mental status, physical and functional performance level should be taken into consideration and the patient should be able to stand up and move as soon as possible [18]. After recovery, patients should be encouraged to practice deep breathing, coughing and in-bed exercises and should be able to get up early. Postoperative early stand up and movement of the patient should not be delayed due to the presence of fluid, drain or chest tube [19]. Planning the activity considering the general condition of the patient undergoing open heart surgery, surgical intervention, hemodynamic, functional and metabolic status is important for the success of surgical intervention and planning of the attempts to improve the quality of postoperative care. In the early postoperative period; Standing up during the first 24 hours is one of the most important prophylactic interventions for the prevention of complications. In many countries around the world, guidelines and algorithms have been developed and actively used to accelerate recovery for different surgical patient groups. An international scientific "network ile for early uprising has been established and up-to-date information and evidence on early mobilization is shared through this network. However, the information contained in these guidelines and the algorithms that facilitate early mobilization are inadequate, even unknown, by the nurses working in the field. As a result of this study, the findings are thought to be useful for health professionals working in cardiovascular surgery clinics in the preparation of early uplifting protocols or care bundles specific to patient undergoing open heart surgery.

\section{Materials and Methods}

\section{Purpose}

The aim of this study was to investigate the postoperative levels of movement and the factors affecting open heart surgery.

\section{Place and time of study}

The sample of the study was carried out in the cardiovascular surgery clinic of a cardiovascular surgery education research hospital between 2 February- 3 May 2019.

\section{Research universe and sample}

This research is descriptive and cross-sectional. The study population consisted of all patients who underwent surgery in the cardiovascular surgery clinic of a cardiovascular surgery training and research hospital. The study sample consisted of patients who underwent surgery within 3 months and met the sampling criteria. Sampling criteria; having open heart surgery, maintaining at least two days postoperative cardiovascular surgery service, being 18 years or older, being literate, being able to discuss the general condition and volunteering to participate in the study. Sample selection was made by one of the improbable sampling methods, convenience sampling method. At the time of sampling, 132 patients meeting the criteria were reached. Five of these patients were under 18 years old and 9 of them had one-day surgery.

\section{Data collection and tools}

The patient was interviewed in the patient room. The interview was completed in about 15 minutes. As a data collection tool, patients' mobility levels and difficulties during movement were evaluated using Patient Mobility Scale and Observer Mobility Scale and Patient Information Form.

I. First, patients were asked to assess their mobility levels and difficulties in moving during the postoperative period using the Patient Mobility Scale.

II. Blood pressure, pulse and respiratory values were obtained before the patients were moved. Blood pressure, pulse and respiratory values were re-measured 20-30 minutes after mobilization.

III. After the follow-up of life signs and movement of the patient, the level of movement of the patients was evaluated by the researcher using the Observer Mobility Scale.

IV. In the scope of the research, mobilization was performed under the supervision of the patient's own physician and after the approval of the physician. 
Patient Information Form was prepared by the researcher. The questionnaire includes questions to determine patients personal, health status, and surgery-related characteristics. Patient Mobility Scale and Observer Mobility Scale: Heye etal.(2002) [20] and Patient Mobility Scale and Observer Mobility Scale; It was developed to measure patient perceptions and objective observations regarding mobility after surgical intervention. The validity- reliability study of the Turkish version of the scale was conducted by Ayoğlu [21].

Patient Mobility Scale: Patient Mobility Scale evaluates the pain and difficulty level caused by 4 activities performed after surgery (turning from one side to the other, sitting on the bedside, standing up on the bedside and walking in the patient's room) [20]. The numerical value of the degree of pain and difficulty was determined by measuring the distance between the mark and 0 placed on the scale with a calibrated ruler. For each activity, two subgroup questions were directed to the patients. The five-point likert type measuring pain perception levels and severities [(1) had no pain, (2) had some pain, (3) had moderate pain, (4) had much pain, (5) was the worst pain I could imagine] Similarly, the degree of difficulty of the activities is answered as five-point Likert type [(1) It was very easy, (2) It was easy, (3) It was a little hard, (4) It was hard, (5) It was hard [21]. The scores obtained give the patient's mobility score for each activity [20]. At the end of the study, to obtain the Total Patient Mobility score, the scores for all activities are calculated by adding up [20]. The lowest and highest scores that can be obtained from each item are between 0-15 and the total scale score is between 0-120 [21]. Scale scores for the answers of the questions in the study indicate that pain and difficulty related to activity increased. In the validity-reliability study, the Cronbach alpha internal consistency coefficient of the Patient Mobility Scale was 0.90 [21]. In this study, Cronbach alpha internal consistency coefficient was 0.84 and item-total score correlation coefficients were found to be between 0.73 and 0.82 for all items. Observer Mobility Scale: During the four activities after surgery, dependence independence status/grade is scored between 1 and 5. As a scale score 1 , he/she has performed the activity independently without verbal stimulation or physical help; The number 5 indicates that the patient has failed to perform the relevant activity despite verbal stimulation or physical assistance. Turning, sitting, standing and walking scores are added and the average score value is calculated [20]. Total Observer Mobility score is obtained by summing the scores of the four activities in the scale. The lowest and highest scores that can be obtained from the scale are between 1-5 and the total score is between 4-20. The increase in the score indicates that the mobility of the patients is insufficient, and the decrease in the score indicates that their ability to move after surgery is good/ sufficient $[20,21]$. In the validity-reliability study, the Cronbach alpha internal consistency coefficient of the Observer Mobility Scale was found to be 0.73 [21]. In this study, Cronbach alpha internal consistency coefficient was 0.86 and item-total score correlation coefficients were between 0.76 and 0.84 .

\section{Ethical aspects of research}

In this study, work permit was obtained from the ethics committee of the university where the researcher was working and the management of the hospital where the study was conducted (Ethics approval no: 2019/02)The purpose of the study was explained to the patients participating in the study. After it was stated that the participation was on a voluntary basis, the consent of the patients willing to participate in the study was obtained.

\section{Statistical analysis of data}

Data were analyzed using SPSS (Statistical Package for Social Sciences) 25.0 program. Descriptive statistics such as frequency, arithmetic mean, standard deviation and percentage were used to analyze personal characteristics and scale mean scores. The normal distribution of the data was analyzed by Kolmogorov-Smirnov test before the analysis and it was found that it showed normal distribution. " $\mathrm{t}$ " test for two independent variables In case of more than two variables, Oneway Anova test and Bonferroni test were used to determine the group causing the difference. Cronbach's alpha test was used to determine the internal consistency coefficients of the scale. Statistical significance was accepted as $p$ $<0.05$.

\section{Limitations of Research}

One of the limitations of this study is that the data on movement levels of patients are limited with the instruments used in the study. Another limitation of this study is that it provides information about the movement levels of patients undergoing only cardiac surgery, orthopedic and general surgery.

\section{Results}

\section{Findings regarding individual characteristics of participants}

It was determined that $64.4 \%$ of the patients were male and $22.9 \%$ were between $60-69$ and $21.2 \%$ were between $50-59$ years. $81.4 \%$ of the patients were married, $40.7 \%$ were high school graduates and $29.7 \%$ were primary school graduates. It was determined that $70.3 \%$ of the patients had chronic disease and $37.3 \%$ of them had hypertension (Table 1).

\section{Findings regarding physical activity and movement level of patients in the postoperative period}

The patients were evaluated according to the Observer Mobility Scale. For each item included in the scale, observers (nurses caring for the patient) were answered according to the ability of the patients to perform the behavior by scoring between 1 and 5 from "independently walked" to "could not walk despite help". $71.2 \%$ of the patients had verbal stimulation and independent movement in the bed from one side to the other, $28.8 \%$ had verbal warning and independent sitting on the bedside. It was determined that $27.1 \%$ and $20.3 \%$ of the patients were sitting on the bed by 
physical assistance and $17.8 \%$ of them stood up and walked. $33 \%$ of the patients were able to move and walk from one side to the other in the bed with the help of the nurse. $6.8 \%$ of them could not walk despite the help and could not move in bed. There were no patients in the bed who were able to perform their functions with independent and verbal stimulation, turning from one side to the other and sitting on the bedside (Table 2). The highest score of the patients from the Observer Mobility Scale was taken from one side to the other in the bed, while the lowest score was taken from the walking room in the patient's room. The mean score of the patients was $11.82 \pm 2.22$ (Table 2).

Table 1: Individual characteristics of the participants $(\mathrm{N}=118)$.

\begin{tabular}{|c|c|c|c|}
\hline \multicolumn{2}{|r|}{ Features } & Number & \multirow[t]{2}{*}{$\%$} \\
\hline \multirow{8}{*}{ Age group } & \multicolumn{2}{|c|}{ The mean age was 53.64 \pm 6.07 . (Distribution 20-79) Hospitalization Day: $3.21 \pm 2.07$} & \\
\hline & $20-29$ & 3 & 2.5 \\
\hline & 30-39 & 22 & 18.6 \\
\hline & $40-49$ & 26 & 22 \\
\hline & $50-59$ & 25 & 21.2 \\
\hline & $60-69$ & 27 & 22.9 \\
\hline & $70-79$ & 15 & 12.8 \\
\hline & Total & 118 & 100 \\
\hline \multirow{3}{*}{ Gender } & Female & 42 & 35.6 \\
\hline & Male & 76 & 64.4 \\
\hline & Total & 118 & 100 \\
\hline \multirow{3}{*}{ Marital status } & The married & 96 & 81.4 \\
\hline & Single & 22 & 18.6 \\
\hline & Total & 118 & 100 \\
\hline \multirow{3}{*}{ Hospital History } & Yes & 73 & 61.8 \\
\hline & No & 45 & 38.1 \\
\hline & Total & 118 & 100 \\
\hline \multirow{3}{*}{ Surgical History } & Yes & 66 & 56 \\
\hline & No & 52 & 44 \\
\hline & Total & 118 & 100 \\
\hline \multirow{5}{*}{ Education level } & Primary school & 35 & 29.7 \\
\hline & High school & 48 & 40.7 \\
\hline & Associate & 19 & 16.1 \\
\hline & License & 16 & 13.5 \\
\hline & Total & 118 & 100 \\
\hline \multirow{6}{*}{ Presence of Chro } & Yes (hypertension, diabetes, etc.) & 83 & 70.3 \\
\hline & No & 35 & 29.7 \\
\hline & Total & 118 & 100 \\
\hline & Hypertension & 44 & 37.3 \\
\hline & Diabetes & 14 & 11.9 \\
\hline & Coronary artery disease & 15 & 12.8 \\
\hline \multirow[t]{4}{*}{ Chronic Di } & Gastro esophageal reflux & 4 & 3.4 \\
\hline & Respiratory system diseases & 3 & 2.5 \\
\hline & Other (kansa, epilepsy, migraine) & 3 & 2.5 \\
\hline & Total & 118 & 100 \\
\hline
\end{tabular}


Table 2: Distribution of findings related to observer mobility scale items independently $(N=118)$.

\begin{tabular}{|c|c|c|c|c|c|c|c|}
\hline & $\begin{array}{l}\text { Independent } \\
\text { Walking }\end{array}$ & $\begin{array}{l}\text { Walked inde- } \\
\text { pendently with } \\
\text { verbal warning }\end{array}$ & $\begin{array}{l}\text { Walked with } \\
\text { verbal warning } \\
\text { and physical } \\
\text { assistance }\end{array}$ & $\begin{array}{l}\text { Dependent on } \\
\text { the nurse to walk }\end{array}$ & $\begin{array}{l}\text { He couldn't } \\
\text { walk despite } \\
\text { help }\end{array}$ & Mean \pm SD & Min-Max \\
\hline & n (\%) & n (\%) & n (\%) & n (\%) & n (\%) & & \\
\hline $\begin{array}{l}\text { Turning from one } \\
\text { side to the other in } \\
\text { the bearing }\end{array}$ & - & $84(71.2)$ & $41(34.7)$ & $39(33)$ & $8(6.8)$ & $3.21 \pm 0.46$ & $2-5$ \\
\hline Sitting by the bed & - & $34(28.8)$ & $32(27.1)$ & $36(30.5)$ & $4(3.4)$ & $3.12 \pm 0.11$ & $2-5$ \\
\hline $\begin{array}{l}\text { By the bed on one's } \\
\text { legs }\end{array}$ & - & - & $24(20.3)$ & $25(21.2)$ & $3(2.5)$ & $3.04 \pm 0.62$ & $1-5$ \\
\hline $\begin{array}{l}\text { Patient walking in } \\
\text { the room }\end{array}$ & - & - & $21(17.8)$ & 18(18.8) & $3(2.5)$ & $2.45 \pm 1.03$ & $1-5$ \\
\hline \multicolumn{6}{|c|}{ Total scale } & $11.82 \pm 2.22$ & $6-20$ \\
\hline
\end{tabular}

The patient mobility scale items were evaluated for the degree of pain and difficulty. In this assessment, for each item, patients responded from 1 to 5 , starting from to no pain to "the worst pain göre according to the degree of pain they felt when performing the behavior. Accordingly, $52.8 \%$ of the patients $(3.65 \pm 0.87)$ felt moderate pain while performing the rotation movement from one

Table 3: Findings of pain mobility and difficulty of patient mobility scale Items $(\mathrm{N}=118)$.

\begin{tabular}{|c|c|c|c|c|}
\hline & \multicolumn{3}{|c|}{ Feeling Pain } & \multicolumn{2}{c|}{ Difficulty Living } \\
\cline { 2 - 5 } & Mean & SD & 3.87 & 0.88 \\
\hline $\begin{array}{c}\text { Turning from one side of the bed } \\
\text { to the other }\end{array}$ & 3.65 & 0.87 & 3.57 & 0.98 \\
\hline Sitting on the edge of the bed & 3.75 & 0,05 & 4.21 & 0.21 \\
\hline Stand up & 4.01 & 0,90 & 4.16 & 1.02 \\
\hline Patient walking in the room & 4.32 & & $31.07 \pm 4.13$ & \\
\hline Scale Total Score & & & \\
\hline
\end{tabular}

In addition, for each item, patients responded from 1 to 5 , starting from "very easy, to "very difficult göre according to the degree of difficulty they experienced in performing the behavior. Accordingly, $45 \%(3.87 \pm 0.88)$ of the patients had difficulty in performing the rotation function from one side to the other in the bed; $37.5 \%(3.57 \pm 0.98)$ had "difficulty ken while performing the sitting function at the bedside; $48.7 \%$ of the patients had difficulty in performing the function of standing up on the bedside; $37.3 \%$ $(4.21 \pm 0.21)$ of the patients stated that they had some difficulty in performing the walking function in the patient room, while $21.5 \%$ stated that they had difficulty (Table 3). Hasta How difficult was it for you to sit on the bedside?", The lowest average score obtained side to the other in the bed, $48.3 \%(3.75 \pm 0.84)$ of the patients felt very painful while performing the sitting movement on the bed, $51.2 \%(4.01 \pm 0.05)$ stated that they felt a lot of pain while standing up on the bedside, and $53 \%(4.32 \pm 0.90)$ felt very painful when performing walking movement in the patient's room (Table 3). from the Patient Mobility Scale items was ne How difficult was it for you to walk in the room?". The mean score of the patients was

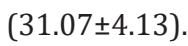

\section{Variables related to physical activity and movement level of patients in the postoperative period}

When patient Mobility Scale and Observer Mobility Scale scores were compared according to gender of the patients, the difference between them was statistically significant $(p<0.05)$. The scores of male patients were significantly higher than the scores of female patients (Table 4). When the Observer Mobility Scale and Patient Mobility Scale scores of the patients were compared according 
to the age group of the patients, the difference between them was statistically significant $(p<0.05)$. Observer Mobility Scale and Patient Mobility Scale scores of the patients were examined. Observer Mobility Scale scores of the patients in the 70-79 age group were significantly higher than the scores of the patients in the 20-59 age group (Table 4).

When the patients' Observer Mobility Scale scores and Patient Mobility Scale scores were compared according to the educational level of the patients, the difference was found to be statistically significant $(\mathrm{p}<0.05)$.Observation Mobility Scale scores of the high school graduates were found to be significantly higher than the scores of primary school, associate and undergraduate graduates. When the Observer Mobility Scale and Patient Mobility Scale scores of the patients were compared according to the marital status of the patients, the difference was found to be statistically significant $(p<0.05)$. The mean scores of both scales of the married patients were significantly higher than the scores of single patients. When the Observer Mobility Scale and Patient Mobility Scale scores of the patients were compared according to their chronic disease status, the difference was found to be statistically significant ( $p$ $<0.05$ ). Observer Mobility Scale and Patient Mobility Scale scores of patients with chronic disease were significantly higher than those of patients without chronic disease (Table 4).

Table 4: Comparison of the means of observer mobility scale and patient mobility scale according to personal characteristics of the patients $(\mathrm{N}=118)$.

\begin{tabular}{|c|c|c|c|c|c|}
\hline \multicolumn{2}{|c|}{ Gender } & \multicolumn{2}{|c|}{ Observer Mobility Scale } & \multicolumn{2}{|c|}{ Patient Mobility Scale } \\
\hline Female & 42 & $10.33 \pm 2.09$ & $t=2,563$ & $23.53 \pm 7.07$ & $\mathrm{t}=1.152$ \\
\hline Male & 76 & $14.82 \pm 3.17$ & $\mathrm{p}=0.47$ & $28.09 \pm 5.27$ & $\mathrm{p}=0.021$ \\
\hline \multicolumn{6}{|c|}{ Age group } \\
\hline $20-29$ & 3 & $10.11 \pm 3.06$ & & $25.00 \pm 3.31$ & \\
\hline 30-39 & 22 & $11.00 \pm 1.95$ & $F=2,563$ & $25.03 \pm 2.81$ & \\
\hline $40-49$ & 26 & $12.50 \pm 2.10$ & $\mathrm{p}=0.000$ & $24.63 \pm 1.46$ & $F=2,461$ \\
\hline $50-59$ & 25 & $12.85 \pm 2.94$ & & $27.95 \pm 4.15$ & $\mathrm{p}=0.012$ \\
\hline $60-69$ & 27 & $15.53(2,3,4) \pm 1.53$ & & $32.65 \pm 5.73$ & \\
\hline $70-79$ & 15 & $14.00(2) \pm 2.95$ & & $29.00 \pm 4.15$ & \\
\hline \multicolumn{6}{|c|}{ Education level } \\
\hline Primary school & 35 & $10.96 \pm 2.68$ & & $31.48(2,3) \pm 6.10$ & \\
\hline High school & 48 & $14.32 \pm 2.93$ & $F=2,563$ & $26.32 \pm 7.06$ & $\mathrm{~F}=2.345$ \\
\hline Associate degree & 19 & $10.78 \pm 3.15$ & $\mathrm{p}=0.001$ & $25.67 \pm 8.79$ & $\mathrm{p}=0.002$ \\
\hline License & 16 & $10.17 \pm 0.98$ & & $21.67 \pm 4.67$ & \\
\hline \multicolumn{6}{|c|}{ Marital status } \\
\hline The married & 96 & $13.79 \pm 3.10$ & $t=2.069$ & $29.23 \pm 7.19$ & $t=3.110$ \\
\hline Single & 22 & $10.42 \pm 2.03$ & $\mathrm{p}=0.004$ & $23.92 \pm 6.38$ & $\mathrm{p}=0.002$ \\
\hline \multicolumn{6}{|c|}{ Presence of another chronic disease } \\
\hline No & 35 & $10.90 \pm 2.38$ & $t=3.269$ & $25.90 \pm 6.89$ & $t=2.378$ \\
\hline Yes & 83 & $14.13 \pm 2.76$ & $\mathrm{p}=0.008$ & $29.29 \pm 7.45$ & $\mathrm{p}=0.018$ \\
\hline
\end{tabular}




\begin{tabular}{|c|c|c|c|c|c|}
\hline \multicolumn{6}{|c|}{ Hospitalization history } \\
\hline No & 45 & $12.54 \pm 1.78$ & $t=1.594$ & $26.87 \pm 7.50$ & $t=1.620$ \\
\hline Yes & 73 & $15.35 \pm 2.69$ & $\mathrm{p}=0.006$ & $29.23 \pm 6.86$ & $\mathrm{p}=0.16$ \\
\hline \multicolumn{6}{|c|}{ Surgical history } \\
\hline No & 52 & $10.48 \pm 2.61$ & $t=-2.121$ & $27.07 \pm 7.57$ & $t=1.035$ \\
\hline Yes & 66 & $11.02 \pm 3.31$ & $\mathrm{p}=0.023$ & $28.88 \pm 6.77$ & $\mathrm{p}=0.30$ \\
\hline
\end{tabular}

When the Observer and Patient Mobility Scale scores of the patients were compared according to the hospitalization history of the patients, the difference between them was statistically significant $(\mathrm{p}<0.05)$. When the Observer Mobility Scale scores were examined, it was noteworthy that the scores of the patients who were previously hospitalized were significantly higher than those of those who were not previously hospitalized. When the Observer and Patient Mobility Scale scores of the patients were compared according to the previous operation status of the patients, a statistically significant difference was found ( $p<0.05)$. The scores of the patients who had previous surgery were found to be statistically higher than the scores of the patients who had no previous surgery (Table 4). There was a statistically significant correlation between the duration of hospitalization and Observer Mobility Scale scores and Patient Mobility Scale ( $r=0.34, p=$ $0.000 ; r=0.42, p=0.000$, respectively).A statistically significant correlation was found between the Observer Mobility Scale scores and the Patient Mobility Scale scores ( $r=0.84, p=0.000)$.

\section{Discussion}

In postoperative patient care, effective care is required to restore the deteriorated homeostatic balance, to maintain normal functioning of all systems, and to prevent and diagnose early surgery-specific complications [22,23]. Effective pre- and postoperative patient care prevents complications from occurring and enables patients to recover as soon as possible and return to their daily lives [24]. Encouragement to stand up early plays an important role in the patient's early independence in addition to preventing complications. The patient is moved to the extent that he can tolerate and encouraged in his movements [25]. At the same time in the postoperative period, the patient may cause deep breathing, coughing exercises, turning bed and unwillingness to stand up [26]. In addition, the surgical wound itself, immobilization during and during recovery (immobilization), movement restriction, anesthesia and analgesics are among the causes of postoperative complications $[27,28]$. In the postoperative period, complications lead to another complication, resulting in prolonged hospital stay and material losses [29]. Less complications develop in patients supported by postoperative pain management and control, deep breathing exercises, and early mobilization [22]. Health professionals have important roles and responsibilities in preventing early mobilization and providing early mobilization. In one study, it was found that the patients had the most difficulty during sitting movement on the bedside and needed help in performing the sitting movement on the bedside [21]. In this study, in order to mobilize the patients in the postoperative period, during the standup movement ( $4.21 \pm 0.88$ ); they were found to have more difficulty in sitting on the edge of the bed and walking in the patient's room than in the bed. Observer Movement Scale scores; The patients mobilized postoperatively showed that the patient mobility scale had the greatest difficulty during bed turning from one side to the other $(3.21 \pm 0.46)$ and needed help. This result indicates that patients need more support, especially during bed-turning and standing up. Early mobilization after surgery has been suggested to accelerate recovery, reduce hospital stay and morbidity, and reduce the incidence of atelectasis, pneumonia, gastrointestinal disturbance and circulatory problems [30]. Despite these benefits of early standing up, it can cause orthostatic hypotension and pain due to sudden movements, and therefore mobilization can be postponed [31]. It is recommended that a gradual position change should be performed since it facilitates the adaptation of the circulatory system to change during the first standing [21,24]. In a study of male patients after coronary artery bypass graft surgery, patients' blood pressure values were significantly increased [32]. In a study, they applied physiotherapy program to patients after liver transplantation and evaluated the patients' blood pressure, pulse and respiratory rate during the first bed sitting, sitting on the bed, sitting on the bed, sitting outside the bed and walking. Accordingly, they found that patients' blood pressure, respiration and pulse values increased after movement [33].

Patients should be supported in the postoperative period in order to perform their daily activities independently. In a study conducted on 106 patients in order to evaluate the effect of early movement on intestinal function in patients undergoing cholecystectomy and cesarean section, the gender of the individuals who participated in the study and the time to first stand up after the surgery were compared with chi-square test and no statistically significant relationship was found between them [29]. In the present study, when the mean scores of the scales were compared according to the gender of the patients, the mean scores of the male patients $(14.82 \pm 3.17$ and $29.51 \pm 3.5 .04)$ were higher than the female patients $(10.33 \pm 2.09$ and $26.09 \pm 2.09)$. With this finding, it was determined that male patients needed more support for mobilization than women. 
As the age-related changes in the functional capacity of cells, tissues and organs decrease, the risk of postoperative complications increases in elderly individuals due to insufficient homeostatic control mechanisms for stress response and age-related changes [34]. In this study, it was found that the difficulties associated with postoperative mobilization increased in parallel with the increase in age in the postoperative period. It was determined that 60-69 age group patients were more dependent on movement than other age groups. Especially in elderly patients, follow-up and attempts to maintain postoperative mobilization should be continued. In a study conducted in the literature, $81.9 \%$ of 360 patients experienced pain while getting out of bed, $96.4 \%$ coughing due to postoperative pain and $78.3 \%$ moving in order to determine their satisfaction level with the opinions of patients about postoperative pain and nurses' approaches. And $46.7 \%$ had difficulty breathing. In the same study, it was found that $78.3 \%$ of the patients had difficulty in moving [35]. In one study, it was found that the quality of life scores of those with lower secondary and lower levels of education were lower than those of high school and faculty graduates [36]. In this study, it was determined that the patient mobility and observer mobility scale scores increased as the educational level of the patients participating in the study increased. This result suggests that patients with low education should be encouraged to move more postoperatively [37,38]. In Yel's work [37] (2009) that examined the relationship between quality of life and anxiety levels of patients undergoing coronary angiography. She determined that married people had less restrictions in performing their physical activities compared to widows. It was determined that the patients believed that their energy and health levels were better. In this study, it was found that married patients need support in standing up and walking activities in the postoperative period.

The presence of chronic disease in the postoperative period may cause delay in recovery and inability to perform normal daily living activities independently [29]. Mobility of patients accelerates the healing process and reduces the incidence of deep vein thrombosis and respiratory complications [29]. In this study, it was found that patients with other chronic diseases had difficulty during mobilization and mobilization and needed support in the postoperative period. It is thought that factors such as addiction, stress and fear resulting from chronic disease duration may be associated with loss of self-confidence in moving patients and feeling dependent on standing up. All surgical interventions may cause early or late complications that may affect the duration of hospital stay, physical compliance and quality of life. These complications can be prevented to a great extent in the postoperative period with proper care in hospital conditions. It has been reported in the literature that patients suffering from orthopedic surgery have more problems with pain and activity [28]. In the study of Yllmaz and Gürler [35] (2011), 100\% of patients with distectomy surgery, $97.3 \%$ of patients with urinary system surgery and $92.9 \%$ of patients undergoing discectomy were examined. It was found that $69.1 \%$ of patients with cardiovascular surgery had sleep problems and $100 \%$ of patients with cardiovascular surgery, discectomy, hysterectomy and urinary system surgery had difficulty in coughing.

In this study, it was determined that patients had more mobility and mobilization problems in the postoperative period because of open heart surgery and they needed more support. In this study, the mean length of hospital stay was $(3.21 \pm 2.07)$.As the activity and movement levels increase in the postoperative period, it improves the postoperative recovery level and shortens the discharge time. This result is important to suggest that attempts to improve the mobilization level in the postoperative period may positively affect the general condition of the postoperative patients.

\section{Implications for Practice}

Surgical applications, which are frequently used as a treatment method in the healing of patients, have increased in recent years with technological advances in the field of health. With this increase, traditional approaches are being replaced by evidencebased practices in order to reduce morbidity, accelerate recovery and shorten the recovery period after surgical treatment. With these changes in the surgical field, rapid recovery was achieved and hospital stay was significantly shortened. Cardiac surgery is one of the surgical areas where rapid changes occur. Nowadays, the most commonly used method in the surgical treatment of heart diseases is open heart surgery. Open heart surgery; Open heart surgery, which is used in the surgical treatment of heart diseases, is a basic treatment for coronary artery disease, heart valve diseases, congenital lesions and heart transplantation. Early mobilization and mobilization of the patient as soon as possible after surgery prevents complications related to inactivity. Maintaining homeostatic balance and accelerating recovery are important goals of postoperative care. Cardiovascular and respiratory complications associated with surgery are reduced with early uplifting. Wound healing and intestinal peristalsis are supported. The development of thrombophlebitis is prevented and the patient is assured to take care of himself / herself as soon as possible. Despite the effects of early standing up on homeostatic balance and recovery, the patient may not be willing to perform these activities after surgery or may have fears about movement. In the early postoperative period; Standing up during the first 24 hours is one of the most important prophylactic interventions for the prevention of complications. In many countries around the world, guidelines and algorithms have been developed and actively used to accelerate recovery for different surgical patient groups. An international scientific "network ile for early uprising has been established and up-todate information and evidence on early mobilization is shared through this network. However, the information contained in these guidelines and the algorithms that facilitate early mobilization are inadequate, even unknown, by the nurses working in the field. As a 
result of this study, the findings are thought to be useful for health professionals working in cardiovascular surgery clinics in the preparation of early uplifting protocols or care bundles specific to patient undergoing open heart surgery (Table 5).

Table 5: The standard CONSORT 2010 items to the left, with proposed CONSORT-Equity extensions to the right.

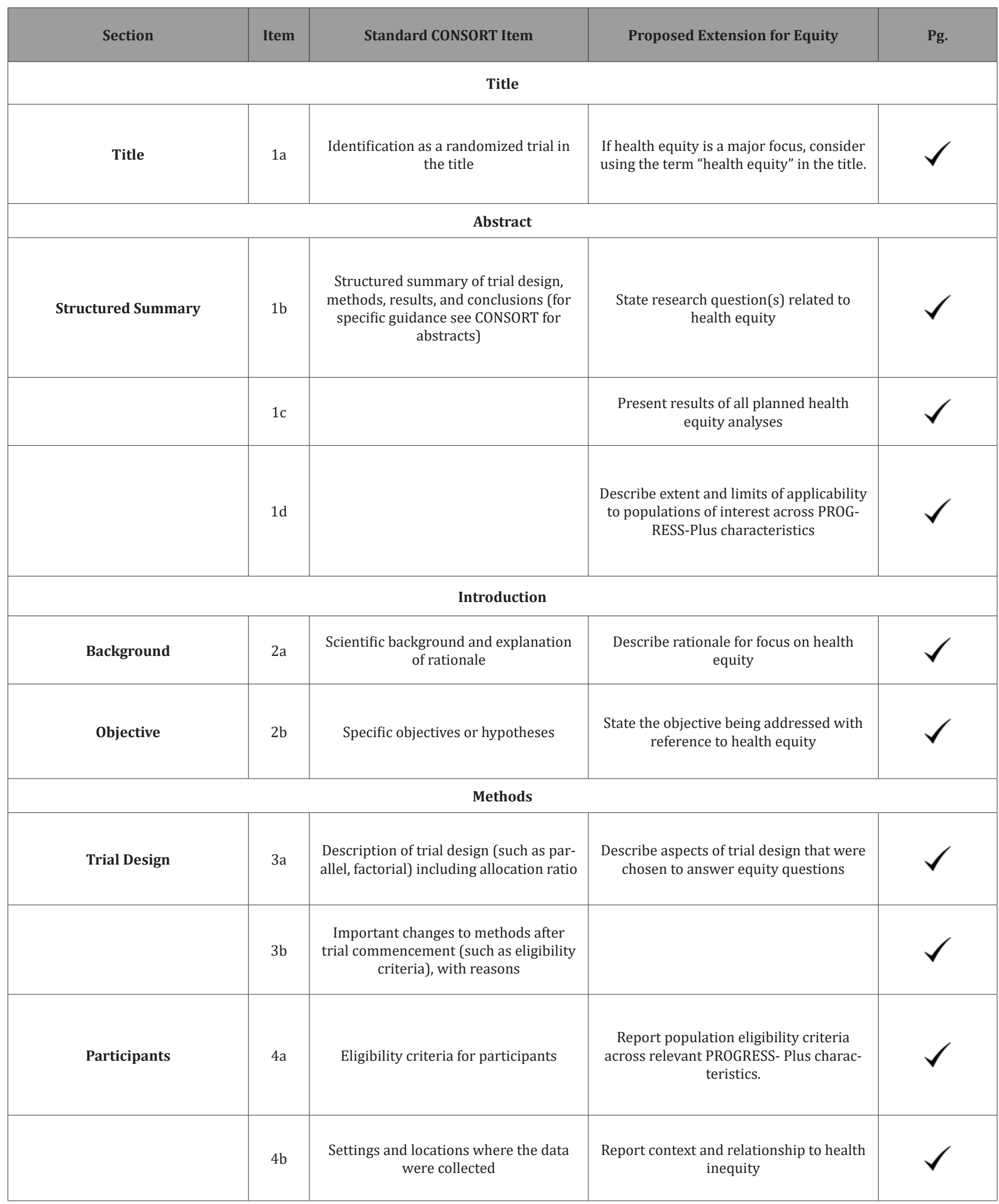




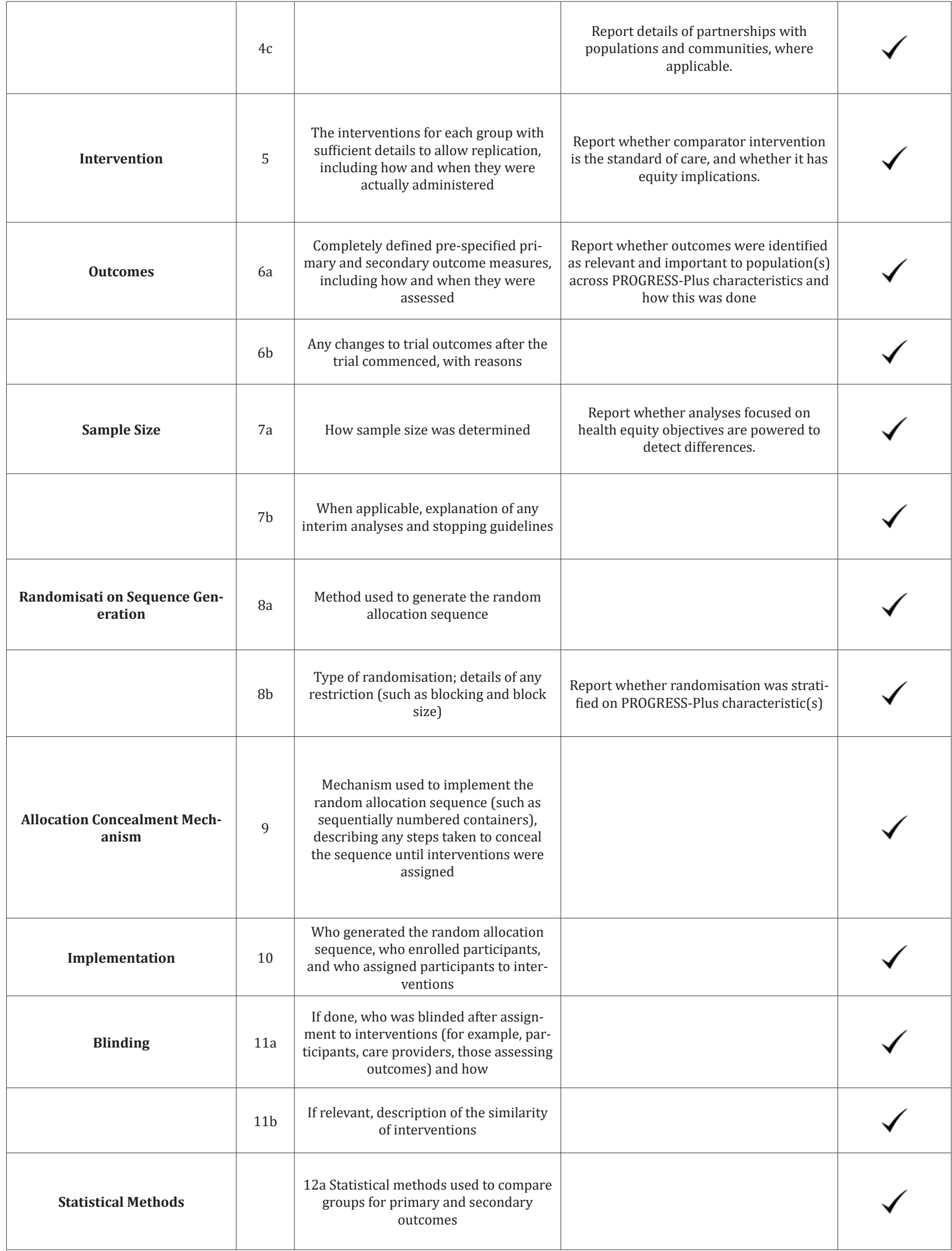




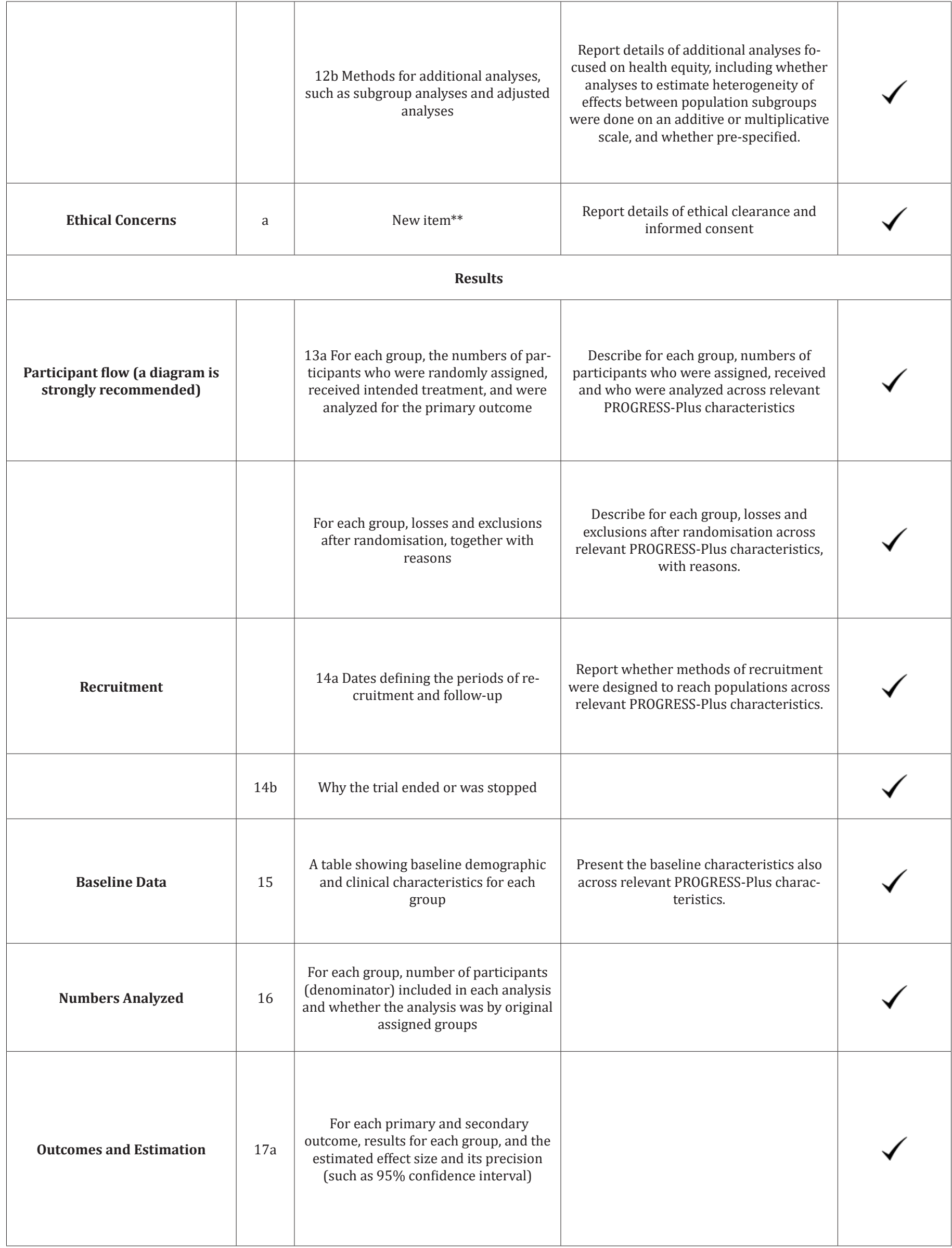




\begin{tabular}{|c|c|c|c|}
\hline & $17 \mathrm{~b}$ & $\begin{array}{l}\text { For binary outcomes, presentation of } \\
\text { both absolute and relative effect sizes is } \\
\text { recommended }\end{array}$ & \\
\hline Ancillary Analysis & & $\begin{array}{l}\text { Results of any other analyses performed, } \\
\text { including subgroup analyses and adjust- } \\
\text { ed analyses, distinguishing pre-specified } \\
\text { from exploratory }\end{array}$ & $\begin{array}{l}\text { Give the results of additional analytic } \\
\text { approaches related to equity objectives } \\
\text { distinguishing pre-specified from explor- } \\
\text { atory. }\end{array}$ \\
\hline & $18 \mathrm{~b}$ & & $\begin{array}{l}\text { Details of implementation (coverage, } \\
\text { intensity) in each trial arm across relevant } \\
\text { PROGRESS-Plus characteristics }\end{array}$ \\
\hline Harms & 19 & $\begin{array}{l}\text { All-important harms or unintended ef- } \\
\text { fects in each group (for specific guidance } \\
\text { see CONSORT for harms) }\end{array}$ & $\begin{array}{l}\text { Report whether intervention generated } \\
\text { inequities (e.g. unintended effects) were } \\
\text { assessed }\end{array}$ \\
\hline
\end{tabular}

\section{Discussion}

\begin{tabular}{|c|c|c|c|}
\hline Limitation & 20 & $\begin{array}{l}\text { Trial limitations, addressing sources } \\
\text { of potential bias, imprecision, and, if } \\
\text { relevant, multiplicity of analyses }\end{array}$ & $\begin{array}{l}\text { Report any limitations related to assessing } \\
\text { effects on health equity. }\end{array}$ \\
\hline Generalizability & 21 & $\begin{array}{l}\text { Generalizability (external validity, appli- } \\
\text { cability) of the trial findings }\end{array}$ & $\begin{array}{c}\text { In addition, report applicability related } \\
\text { to population of interest across PROG- } \\
\text { RESS-Plus characteristics. }\end{array}$ \\
\hline Interpretation & 22 & $\begin{array}{l}\text { Interpretation consistent with results, } \\
\text { balancing benefits and harms, and con- } \\
\text { sidering other relevant evidence }\end{array}$ & \\
\hline \multicolumn{4}{|c|}{ Other information } \\
\hline Registration & 23 & $\begin{array}{l}\text { Registration number and name of trial } \\
\text { registry }\end{array}$ & \\
\hline Protocol & 24 & $\begin{array}{l}\text { Where the full trial protocol can be } \\
\text { accessed, if available }\end{array}$ & \\
\hline Funding & 25 & $\begin{array}{l}\text { Sources of funding and other support } \\
\text { (such as supply of drugs), role of funders }\end{array}$ & \\
\hline
\end{tabular}




\section{Conclusion}

In this study, it was determined that patients had difficulty in moving at different levels in the postoperative period, and they needed more support and encouragement especially in standing up and walking. In parallel with the increase in age in the postoperative period, it is recommended that elderly patients, especially elderly patients, should be monitored and encouraged to maintain mobilization, since they experience more problems with postoperative mobilization. Preoperative training programs to prevent postoperative complications, surgical intervention, deep breathing, cough, leg exercises, bed rotation, mobilization and pain reduction training should be given. Patients should be encouraged and supported in terms of early mobilization and increased mobility to support postoperative recovery. It is important to ensure cooperation between physician and nurse in early mobilization after surgery and to be under the control of the physician or nurse during the first stand up, to support the patients especially during the rotation of the bed and to train and encourage them to move within the bed. In order to avoid delaying the early mobilization process, in line with the evidence-based data made for early mobilization with the common opinion of physicians and nurses in clinics; It is recommended that a specific procedure and schedule be established considering the nature, general condition and age of the patient's surgery.

\section{Acknowledgement}

None.

\section{Conflict of Interest}

No conflict of interest.

\section{References}

1. King PM, Blazeby JM, Ewings P, Franks PJ, Longman RJ, et al. (2006) Randomized clinical trial comparing laparoscopic and open surgery for colorectal cancer within an enhanced recovery programme. British Journal of Surgery: Incorporating European Journal of Surgery and Swiss Surgery 93(3): 300-308.

2. Gouvas N, Tan E, Windsor A, Xynos E, Tekkis PP, et al. (2009) Fasttrack vs standard care in colorectal surgery: a meta-analysis update. International journal of colorectal disease 24(10): 1119-1131.

3. Bocher MA, Edelman MA, Edmisson KW, March KS, O Conner LJ, et al. (2006) Handbook of Medical Surgical Nursing pp. 208-211.

4. Aslan Eti F (2009) History of the Surgical Nursing. Journal of Atatürk University School of Nursing 12(1): 104-113.

5. Öztekin D (2009) Evidence-Based Recommendations in Postoperative Applications.

6. Büyükyılmaz F, Şendir M (2014) A problem issued in postoperative care: determination of the risk of deep vene thrombosis (dvt) and nursing care. Journal Of Health Sciences 23(1): 48-54.

7. Altınel M, Akinci S (2010) Postoperative care in urologic laparoscopic surgery. Turk Urol Sem (1): 147-152.

8. Ersoy E, Gündoğdu H (2007) Enhanced recovery after surgery. Turkish Journal of Surgery 23(1): 35-40.

9. Vermişli S, Çam K (2015) The efficacy of early mobilization after urologic radical surgery. Bull Urooncol (14): 324-326.

10. Teeuwen PH, Bleichrodt RP, Strik C, Groenewoud JJM, Brinkert W, et al. (2010) Enhanced recovery after surgery (ERAS) versus conventional postoperative care in colorectal surgery. Journal of Gastrointestinal Surgery 14(1): 88-95.

11. Meyer MJ, Stanislaus AB, Lee J, Waak K, Ryan C, et al. (2013) Surgical Intensive Care Unit Optimal Mobilisation Score (SOMS) trial: a protocol for an international, multicentre, randomised controlled trial focused on goal-directed early mobilisation of surgical ICU patients. BMJ open 3(8): e003262.

12. Cameron S, Ball I, Cepinskas G, Choong K, Doherty TJ, et al. (2015) Early mobilization in the critical care unit: a review of adult and pediatric literature. Journal of critical care 30(4): 664-672.

13. Kalisch BJ, Lee S, Dabney BW (2-14) Outcomes of inpatient mobilization: a literature review. Journal of clinical nursing 23(11-12): 1486-1501.

14. Eti Aslan F (2014) Eti Aslan F, Karadakovan A, (eds.), Internal and Surgical Care. Academician Medical Bookstore pp. 279-306.

15. Hoffmann H, Kettelhack C (2012) Fast-track surgery-conditions and challenges in postsurgical treatment: a review of elements of translational research in enhanced recovery after surgery. European Surgical Research 49(1): 24-34.

16. Vann AM (2009) Perioperative management of ambulatory surgical patients with diabetes mellitus. Current Opinion in Anaesthesiology 22: 718-724.

17. Martinez K, Battaglia R, Start R, Mastal MF, Matlock AM (2015) Nursingsensitive indicators in ambulatory care. Nursing Economics 33(1): 59 66.

18. Clini E, Ambrosino N (2005) Early physiotherapy in the respiratory intensive care unit. Respiratory Medicine 99: 1096-1104.

19. Perme C, Chandrashekar R (2009) Early mobility and walking program for patients in intensive care units: Creating a standard of care. American Journal of Respiratory and Critical Care Medicine 18: 212-221.

20. Heye ML, Foster L, Bartlett MK, Adkins S (2002) A Preoperative intervention for pain reduction, improved mobility and self-efficacy. Applied Nursing Research 15(3): 174-183.

21. Ayoğlu T (2011) The effect of pre-surgical training on self-efficacy and healing process. Istanbul University: Institute of Health Sciences.

22. Aktan Ö (2004) Postoperative care. In: Basic surgery. Sayek I (eds.), Ankara: Güneş Bookstore, Turkey.

23. Astarcıoğlu H (2002) Postoperative care. In: Basic surgical sciences with a problem-based learning approach. Tailor C (eds.), Izmir: Dokuz Eylül Publications, Turkey.

24. Erdil F, Ozhan Elbas N (2001) Surgical diseases nursing. Ankara: Aydogdu Offset, Turkey.

25. Bölükbaşı N (2000) Cardiac rehabilitation. In: Physical medicine and rehabilitation. Beyazova M, Gökçe Kutsal Y. (eds.), Ankara: Güneş Bookstore, Turkey.

26. Ignatavicius DD (2006) Critical thinking in the role of the medical-surgical nurse. Medical-surgical nursing: Critical thinking for collaborative care. Ignatavicius DD, Workman ML (eds.), 5th edition Philadelphia: Elsevier Saunders.

27. Özer N, Bölükbaș N (2010) Describing the pain in the postoperative period and examining the interventions of the nurses for the painful patients. Anatolian Journal of Nursing and Health Sciences 4 (1): 1-17

28. Dal Ü, Bulut H, Demir SG (2012) Problems experienced by patients after surgery. Bakırköy Medical Journal 8: 34-40.

29. Cinar V (2005) Evaluation of the effect of early ambulation on intestinal function in patients undergoing abdominal surgery. Afyon Kocatepe University: Health Sciences Institute, Master Thesis. Afyonkarahisar, Turkey. 
30. Eti Aslan F (2020) Postoperative care. In: Internal and care in surgical diseases. Karadakovan A, Eti Aslan F (eds.), Adana: Nobel Bookstore, Turkey.

31. Müller RG, Bundgaard Nielsen M, Kehlet H. (2010) Orthostatic function and the cardiovascular response to early mobilization after breast cancer surgery. British Journal of Anaesthesia 104(3): 298-304.

32. Price P (2006) Physiology effects of first-time sitting among male patients after coronary artery bypass graft surgery. Dynamics 17(1): 12-19.

33. Senduran M, Yurdalan SU, Karadibak D, Gunerli A (2010) Haemodynamic effects of physiotherapy programme in intensive care unit after liver transplantation. Disability and rehabilitation 32(17): 1461-1466.

34. Tails CR, Fillit MH (2003) Geriatric medicine and gerontology. 6th ed. London: Churchill Livingstone, Turkey.
35. Yilmaz M, Gurler H (2011) Nursing approaches to postoperative pain of patients: Patient opinions. Journal of Agri 23(2): 71-79.

36. Göçgeldi E, Babayiğit MA, Hassoy H, Açıkel CH, Tașçı I, et al. (2008) To evaluate the perceived quality of life level of the patients with hypertension and the factors affecting them. Gülhane Journal of Medicine 50(3): 172-179.

37. Yel P (2009) Determination of quality of life and anxiety levels of patients undergoing coronary angiography. Trakya University: Institute of Health Sciences, Master Thesis. Edirne, Turkey.

38. McWilliams DJ, Pantelides KP (2008) Does physiotherapy led early mobilization affect length of stay on ICU. Respir Care J 40: 5-11. 